研究

\title{
Consolidation of Ultrafine Alumina Powders with SPS Method
}

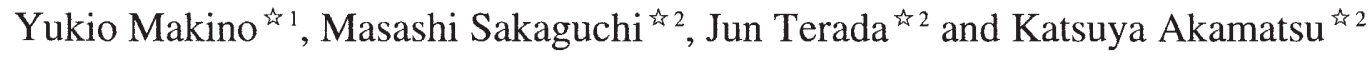 \\ \& 1 Joining \& Welding Research Institute, Osaka university, 11-1 Mihogaoka, Ibaraki 567-0047, Japan. \\ ${ }^{2}$ Department of Materials Science \& Engineering, Kansai University, 3-3-35 Yamate-cho, Suita 564-8680, Japan.
}

Received September 5, 2006

\begin{abstract}
SYNOPSIS
SPS consolidation of two ultrafine $\alpha$-alumina powders (TM-alumina with $100 \mathrm{~nm}$ and AA-alumina with 230 $\mathrm{nm}$ ) was examined under the two pressurizing conditions of $30 \mathrm{MPa}$ and $100 \mathrm{MPa}$. It was found that densification behavior under $30 \mathrm{MPa}$ was influenced by the grain size of raw powder alumina and the influence of grain size on the densification was remarkably suppressed under $100 \mathrm{MPa}$. It was also indicated that the grain growth was fairly suppressed in the consolidation of TM-alumina powder even when the powder was consolidated at a higher temperature than $1300^{\circ} \mathrm{C}$. Further, the growth of crystallite was suppressed by increasing the applied pressure from $30 \mathrm{MPa}$ to $100 \mathrm{MPa}$. Under the condition of $100 \mathrm{MPa}$, nano-structural aluminas with less than $300 \mathrm{~nm}$ and about $500 \mathrm{~nm}$ were synthesized by consolidating TM-alumina at $1150^{\circ} \mathrm{C}$ and AA-alumina at $1200^{\circ} \mathrm{C}$, respectively, indicating that SPS method has high capabilities of synthesizing nano-structured ceramics.
\end{abstract}

KEY WORDS

Nano-structural alumina, SPS, crystallite size, low temperature densification, grain growth

\section{Introduction}

Recently, SPS method has been extensively applied for consolidating various powder materials ${ }^{1-3)}$. Up to present time, various materials such as functionally-graded, thermoelectric, dielectric and hard materials have been synthesized with SPS and its related methods ${ }^{4-7)}$. Thin film ferrite has also been fabricated with SPS method for the purpose of applying to non-reciprocal transmission device $^{8)}$. Further, it has been indicated that remarkable preferential orientation can be generated in the SPSconsolidated nano-structured anatase ${ }^{9-11)}$. Thus, SPS process has been available for consolidation of various powders and their composites, and the consolidation mechanism and physical phenomena in SPS process has been investigated for solving the origin of rapid densification and the suppression of grain growth. For example, effects of process parameters on the characters of materials has been examined in the SPS-sintered alumina, and it has explained that the rapid densification can not be interpreted by only the enhancement of boundary diffusion generated from the direct current field due to pulsed high current ${ }^{12}$. However, necking formation in alumina sintered at a fairly low temperature $\left(\sim 950^{\circ} \mathrm{C}\right)^{13)}$ and suppression of grain growth ${ }^{14)}$ have been observed as the positive evidences on the effect of pulsed high current. Synthesis of nano- structural aluminas by SPS or its related processes has been performed as one of the purpose to examine the effect of high heating rate on the suppression of grain growth ${ }^{15,16)}$.

In the present study, effects of the initial grain size and pressurization on the densification of ultrafine alumina powders were investigated for the purpose of clarifying the sintering behavior in SPS process. Further, capability of synthesizing nano-structural alumina using SPS method was also examined.

\section{Experimental Procedures}

Two sorts of $\alpha$-alumina powders with the average size of $100 \mathrm{~nm}$ and $230 \mathrm{~nm}$ were used as raw materials. Specimen notation of these powders and their chemical compositions are given in Table 1. SPS machine (Dr. Sinter, SPS-1050, Sumitomo Coal Mining Co.) was used as an equipment for sintering. These alumina powders were sintered using graphite die with $20 \mathrm{~mm}$ in inner diameter and punches, respectively. Sintering temperature was varied from $1000^{\circ} \mathrm{C}$ to $1400^{\circ} \mathrm{C}$. Two pressurizing conditions of $30 \mathrm{MPa}$ and $100 \mathrm{MPa}$ were examined and sintering time was fixed at $10 \mathrm{~min}$. Density of sintered alumina was measured by Archimedean method using distilled water. Crystallite size was estimated from line-width of (113) XRD peak of $\alpha$ alumina using Scherrer's equation $(\mathrm{D}=\mathrm{k} \lambda / \beta \cos \theta$; $\mathrm{D}$ : 
Table 1 Notation of raw powder alumunas, their mean particle size, BET specific surface and the contents of main impure elements.

\begin{tabular}{|c|c|c|c|c|c|c|c|}
\hline \multirow{2}{*}{$\begin{array}{l}\text { Specimen } \\
\text { notation }\end{array}$} & \multirow{2}{*}{$\begin{array}{c}\text { Commercial } \\
\text { name }\end{array}$} & \multirow{2}{*}{$\begin{array}{c}\text { Mean } \\
\text { particle } \\
\text { size } \\
\end{array}$} & \multirow{2}{*}{$\begin{array}{c}\text { BET } \\
\text { specific } \\
\text { surface }\end{array}$} & \multicolumn{4}{|c|}{ Content of main impure element } \\
\hline & & & & $\mathrm{Si}$ & $\mathrm{Na}$ & $\mathrm{Mg}$ & $\mathrm{Fe}$ \\
\hline TM-alumina & TMDAR & $100 \mathrm{~nm}$ & $14.5 \mathrm{~m}^{2} / \mathrm{g}$ & 10ppm & 8ppm & 2ppm & 8ppm \\
\hline AA-alumina & AA-02 & $230 \mathrm{~nm}$ & $7.3 \mathrm{~m}^{2} / \mathrm{g}$ & $10 \mathrm{ppm}$ & $\leqq 5 p p m$ & $\leqq \mathrm{lppm}$ & $7 \mathrm{ppm}$ \\
\hline
\end{tabular}

crystallite size, $\mathrm{k}$ : constant $(=0.9), \lambda$ : wavelength of $\mathrm{X}$ ray, $\beta$ : line width, $\theta$ : diffraction angle). XRD measurement was done using a XRD spectrometer (Miniflex, Rigaku Corporation) under $\mathrm{Cu} \mathrm{K} \alpha$ radiation. Microstructure of sintered alumina was observed using fractured surface with a FE-SEM microscope (JEOL, JSM-6330F II) and grain size was estimated by averaging the sizes of several ten grains observed two-dimensionally.

\section{Results and Discussion}

Dependence of relative density on sintering temperature for SPS-consolidated aluminas is shown in Fig. 1. Comparing with two sorts of aluminas, it was found that densification could be easily proceeded in the TM-alumina with the grain size of $100 \mathrm{~nm}$. In the pressuring condition of $30 \mathrm{MPa}$, TM-alumina reached nearly full density at $1200^{\circ} \mathrm{C}$, while AA-alumina with the grain size of $230 \mathrm{~nm}$ could not fully be densified up to $1400^{\circ} \mathrm{C}$. However, similar densification behavior was found in the condition of $100 \mathrm{MPa}$ except for the appearance of some difference near $1150^{\circ} \mathrm{C}$.

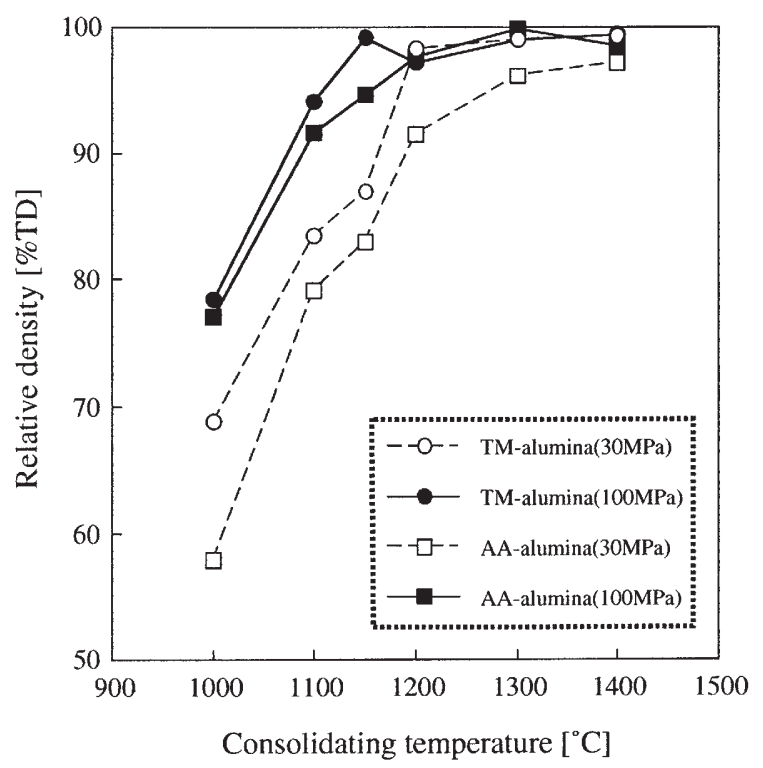

Fig.1 Dependence of relative density on consolidating temperature in SPS-consolidated TM- and AA-aluminas.
Accordingly, the densification behavior of alumina in SPS consolidation can be influenced by the grain size in such a low pressurizing condition as $30 \mathrm{MPa}$ and the increase of the pressure remarkably decreases the influence due to the difference of grain size, as shown in the case of $100 \mathrm{MPa}$.

Fig. 2 shows the relation between crystallite size and sintering temperature for SPS-consolidated aluminas. It was found that the crystallite size remarkably grew in both aluminas when the sintering temperature exceeded $1150^{\circ} \mathrm{C}$. The remarkable growth of crystallite corresponds to the attainment of nearly full densification, as shown in Fig. 1. When the pressure increased up to $100 \mathrm{MPa}$, however, remarkable suppression of the crystallite size in both aluminas was observed. In other words, rapid growth of crystallite under $30 \mathrm{MPa}$ occurs before full densification and the crystallite growth occurs gradually under $100 \mathrm{MPa}$ irrespective of proceeding densification.

According to our previous result ${ }^{17)}$, suppression of crystallite growth has been observed in the dense nanostructured anatase consolidated with SPS method. Further,

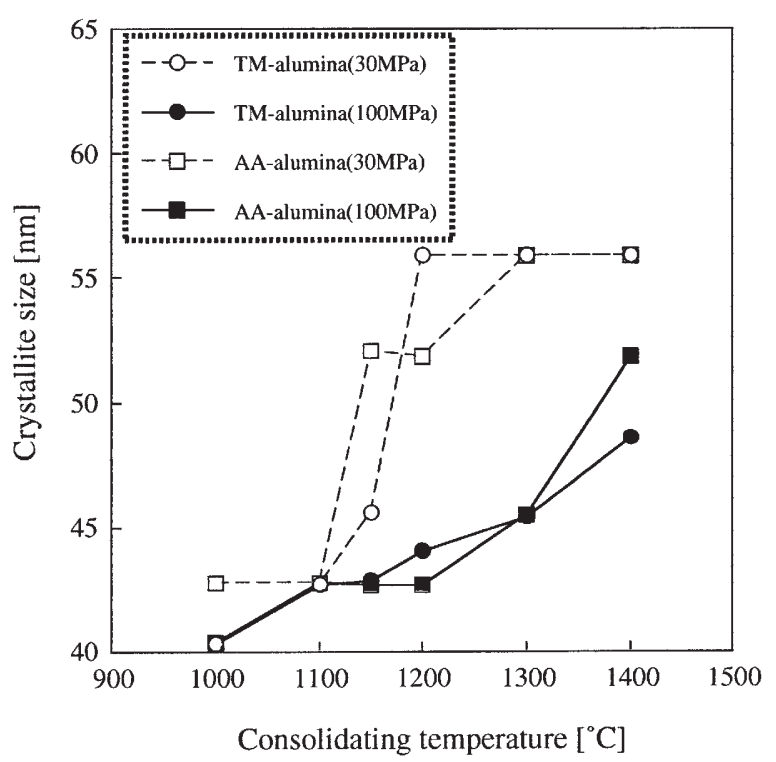

Fig.2 Dependence of crystallite size on consolidating temperature in SPS-consolidated TM- \& AA-aluminas. 
it has indicated that neglect of internal strain in SPSconsolidated anatase underestimates the value of crystallite size only by about $5 \mathrm{~nm}$ when the effect of internal strain was examined by comparing crystallite sizes, which were estimated on the basis of Scherrer and Scherrer-Wilson methods. Furthermore, the internal strain calculated by
Scherrer-Wilson method has been estimated to be below $0.1 \%$. Thus, suppression of crystallite growth is one of characteristics in the SPS-consolidated ceramics, though the occurrence of suppression depends on pressure.

Subsequently, Figs. 3 and 4 show SEM microstructures of TM-and AA-aluminas consolidated at various
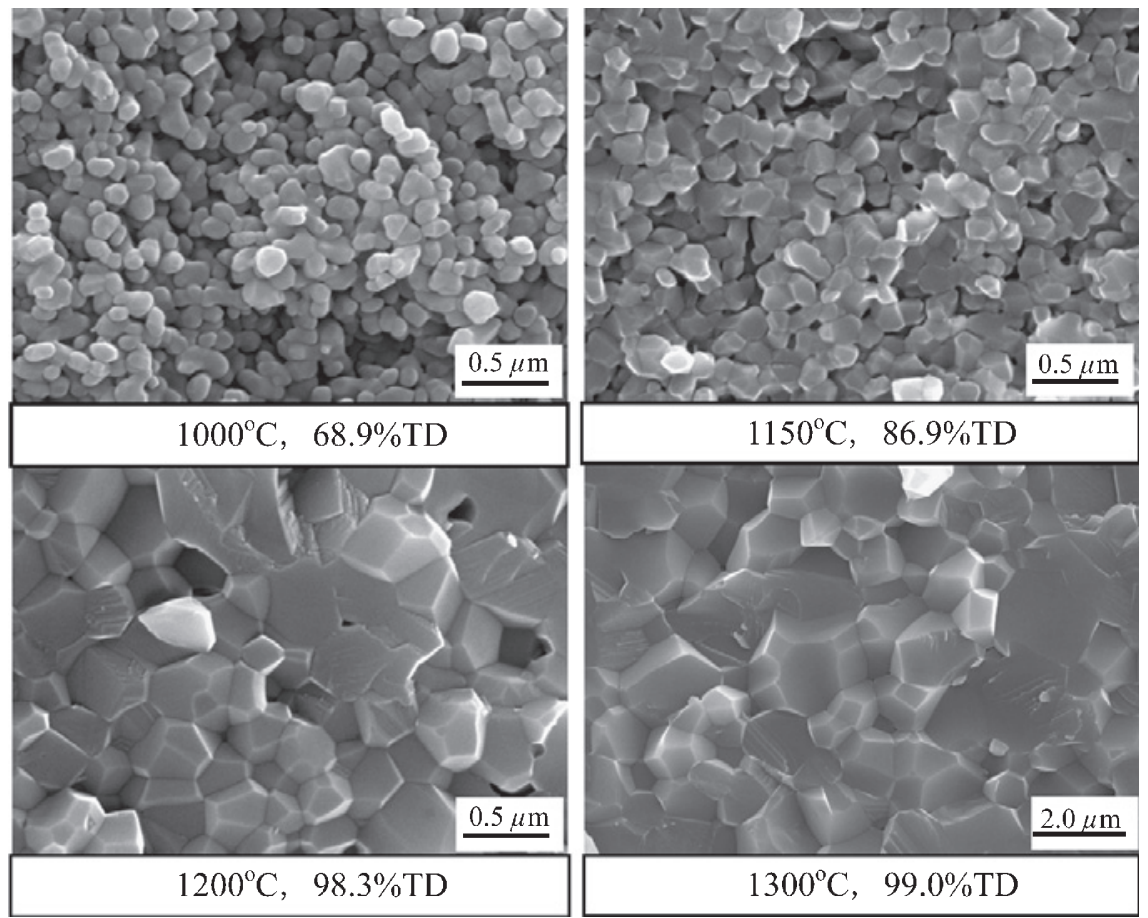

Fig.3-(a) SEM images of the fractured surfaces of TM-aluminas consolidated under 30MPa by SPS method.
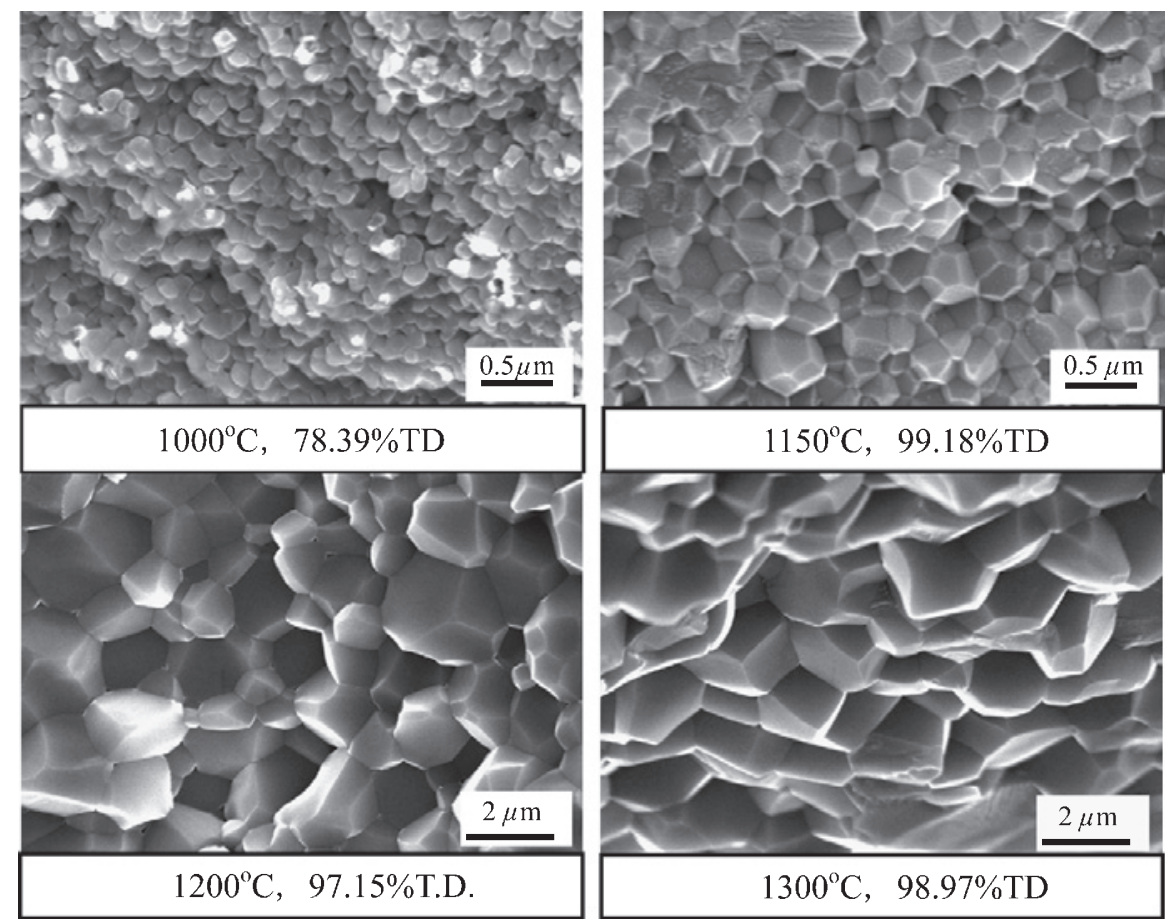

Fig.3-(b) SEM images of the fractured surfaces of TM-aluminas consolidated under 100MPa by SPS method. 


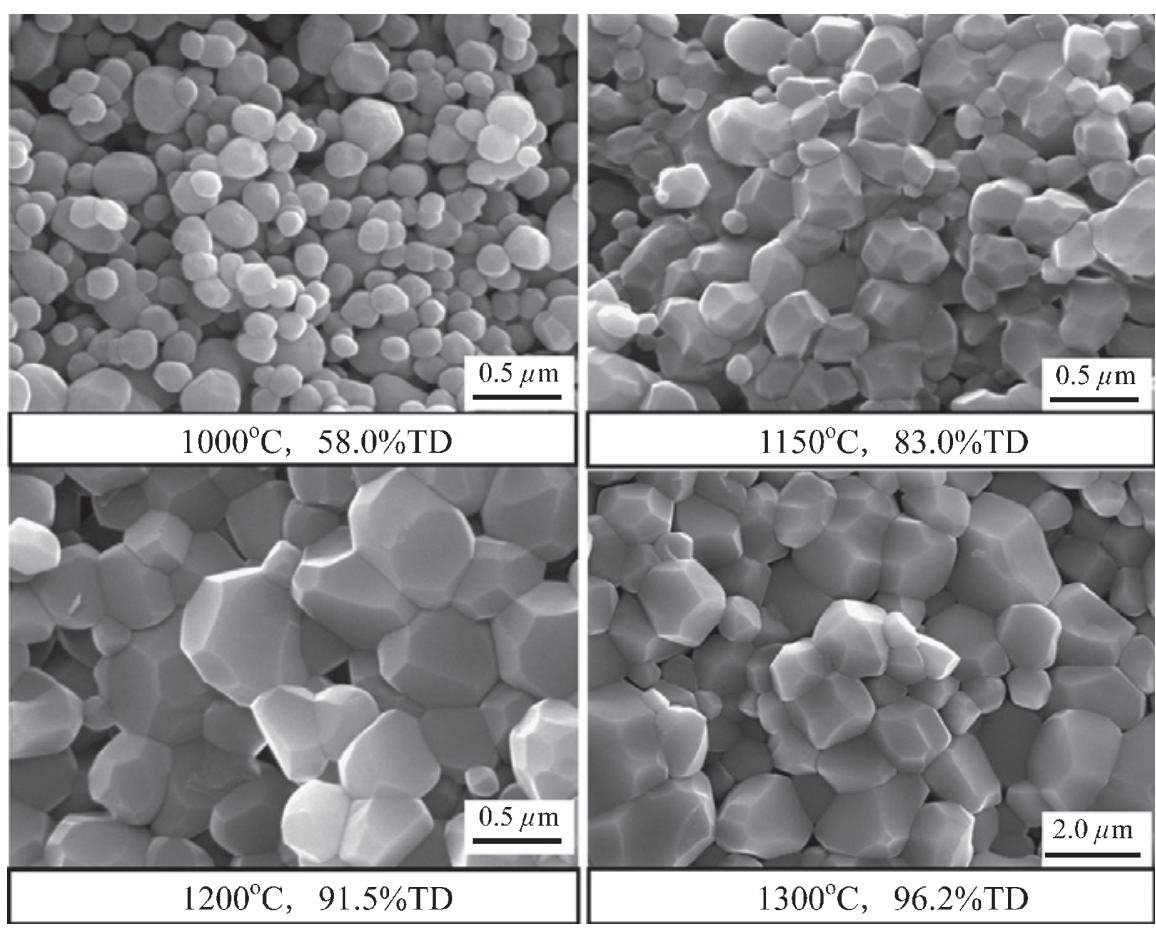

Fig.4-(a) SEM images of the fractured surfaces of AA-aluminas consolidated under 30MPa by SPS method.
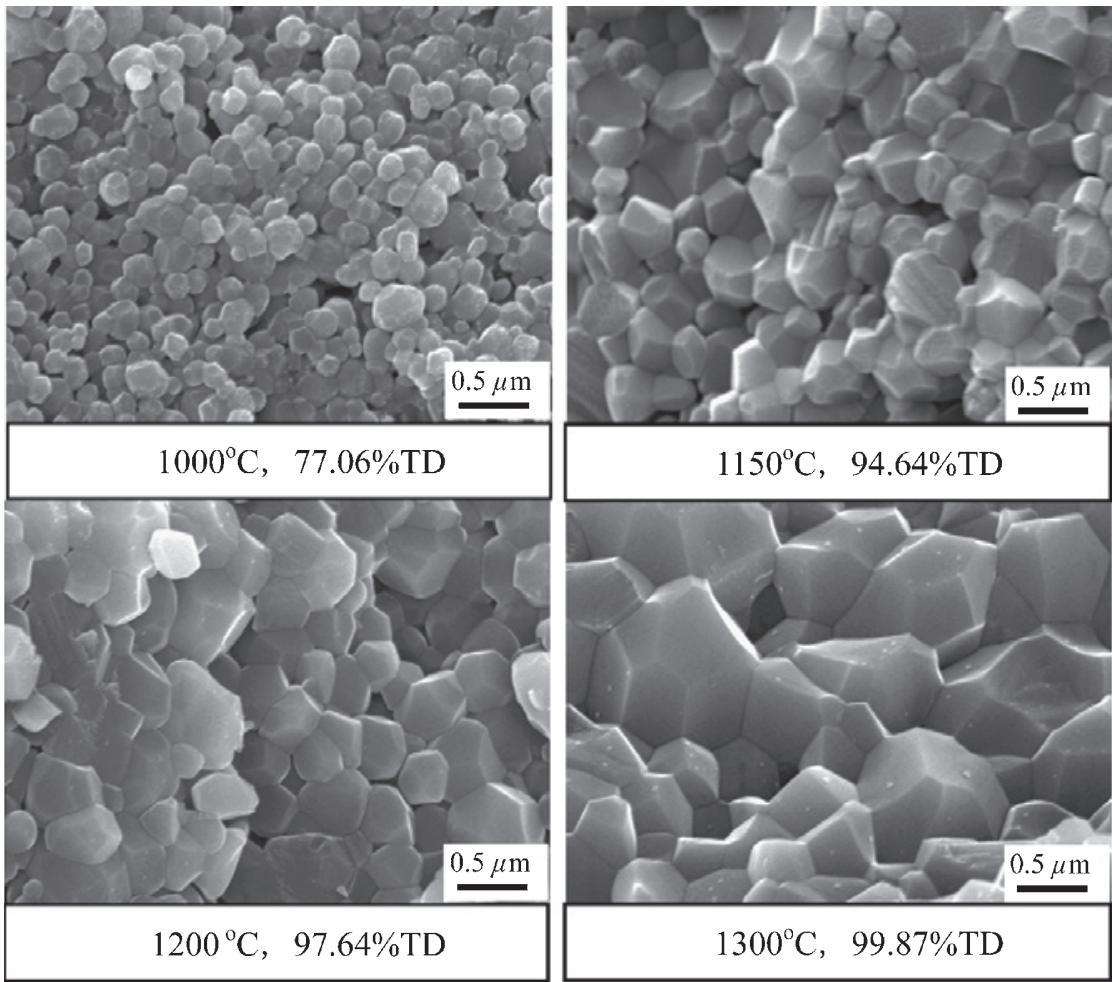

Fig.4-(b) SEM images of the fractured surfaces of AA-aluminas consolidated under 100MPa by SPS method.

temperatures. Dependence of apparent grain size, which is estimated from the SEM image, on the consolidating temperature is shown in Fig. 5. From these results, TMalumina attains full densification over $99 \% \mathrm{TD}$ at $1150^{\circ} \mathrm{C}$ in the consolidating at $100 \mathrm{MPa}$ and consolidation at higher temperature than $1150^{\circ} \mathrm{C}$ only proceeds grain growth. It was also found that the average grain size could be suppressed to be less than $2 \mu \mathrm{m}$ in the TM-alumina 


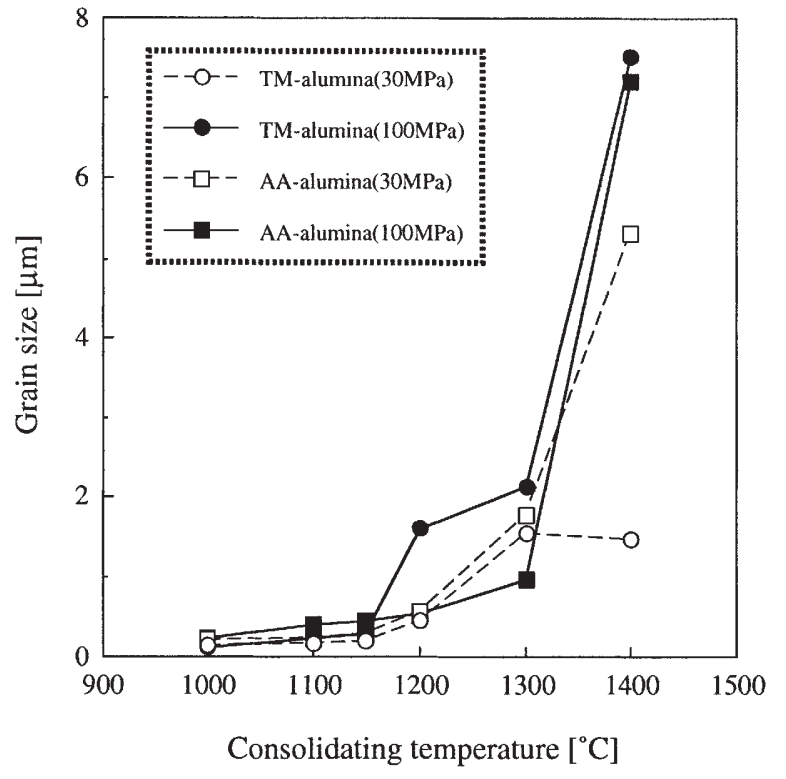

Fig.5 Dependence of grain size on the consolidating temperature in SPS-consolidated TM- \& AA-aluminas

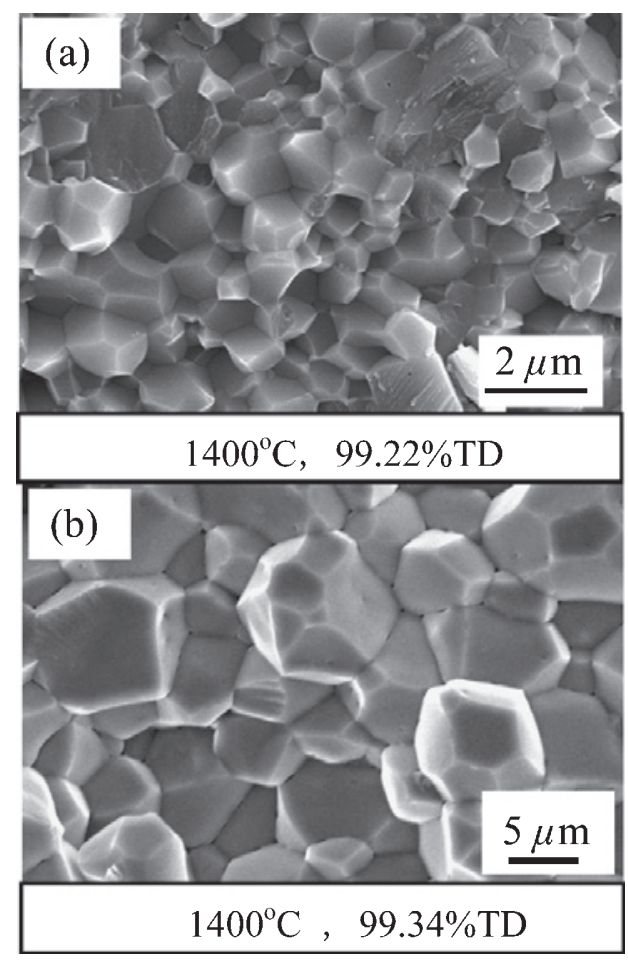

Fig.6 SEM images of the fractured surfaces of TM-aluminas consolidated at $1400^{\circ} \mathrm{C}$ under (a) $30 \mathrm{MPa}$ and (b) $100 \mathrm{MPa}$.

consolidated at $30 \mathrm{MPa}$ even when the alumina was consolidated at $1400^{\circ} \mathrm{C}$, as shown in Fig. 6. Accordingly, fine-grained alumina can be synthesized at $30 \mathrm{MPa}$ in the wide range of consolidating temperature using SPS method. Further, under the condition of $100 \mathrm{MPa}$, nano-structural

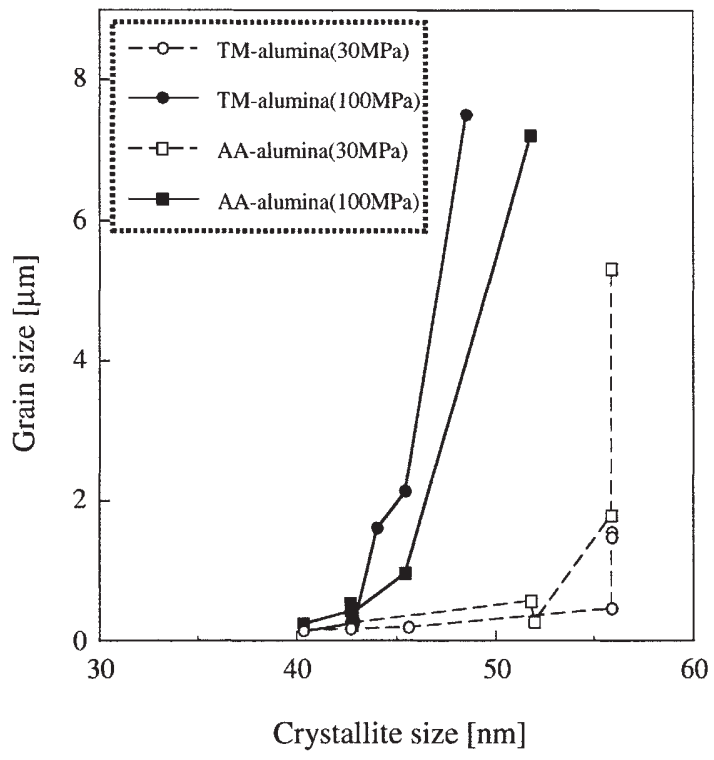

Fig.7 Relation between crystallite size and grain size in SPSconsolidated TM- \& AA-aluminas.

and dense alumina with ultrafine grain less than $300 \mathrm{~nm}$ can be synthesized at $1150{ }^{\circ} \mathrm{C}$. On the other hand, in the AA-alumina with the average size of $230 \mathrm{~nm}$, it is shown that nano-structural and dense alumina was obtained at $1200^{\circ} \mathrm{C}$, which is $50^{\circ} \mathrm{C}$ higher consolidating temperature than that in TM-alumina. Further, as shown in SEM images, polyhedral grains with clear habit planes are observed at a fairly low temperature in the nano-structure of TM-alumina, compared with those in AA-alumina.

Comparing with behaviors of crystallite growth against pressure or sintering temperature, behaviors of grain growth show different dependence. As shown in Fig. 2, crystallite growth shows similar dependence against pressure or sintering temperature in both TM- and AAaluminas, suggesting similar intragranular mass transfer. On the contrary, a fairly different intergranular behavior in these aluminas is suggested from the dependence of grain growth on the sintering temperature and the difference is not simply attributed to the difference in grain size.

In general, the growth of crystallite occurs prior to the growth of grain because misfit energy between crystallites is smaller than that between grains. Accordingly, crystallite begins to grow in the intermediate stage of sintering and grain growth occurs in the final stage of sintering. Different dependence is obtained in the relations between crystallite and grain sizes at $30 \mathrm{MPa}$ and $100 \mathrm{MPa}$, as shown in Fig. 7 . The different dependence is attributed to the fact that the final stage of sintering under $100 \mathrm{MPa}$ begins at around 
$1150^{\circ} \mathrm{C}$ and the grain growth evolves with the growth of crystallite. While, under the condition of $30 \mathrm{MPa}$ at a temperature less than $1200^{\circ} \mathrm{C}$, only crystallite growth occurs predominantly because sintering is in the intermediate stage. However, the low rate grain growth of TM-alumina at the higher temperature than $1300^{\circ} \mathrm{C}$ can not be interpreted by the misfit energy. Another reasons such as plastic flow or pulsed high current effect on ultrafine powder should be verified in further investigation.

Sintering of $\alpha$-alumina by SPS method has been performed from the various standpoints. Up to the present time, various investigations such as dependence of densification behavior on process factors ${ }^{18)}$, estimation of microstructure inhomogeneity ${ }^{19}$, attainment of high bending strength ${ }^{20)}$ have been reported. Though nanostructural $\alpha$-alumina with no additives has not been so extensively synthesized by the process related with pulsed high current, it has been tried to synthesize using the electric pulse assisted (EPA) consolidation method. According to the results by Mishra et al. ${ }^{21)}, \alpha$-alumina with $700 \mathrm{~nm}$ grain size was obtained by EPA consolidation at $1300^{\circ} \mathrm{C}$ from nano-powder $\alpha$-alumina of $50 \mathrm{~nm}$. It has also reported that decrease of the grain size to $500 \mathrm{~nm}$ can be attained by the addition of small amount of $\mathrm{MgO}$ to the same nanopowder $\alpha$-alumina. Further, $\alpha$-alumina with the average size of $650 \mathrm{~nm}$ has been synthesized using PAS method by the same group ${ }^{22)}$. In the sintering of submicron $\alpha$-alumina powder, several investigations on the relation between densification and grain growth have also been reported. For example, Shen et al. ${ }^{12)}$, investigated the consolidation of $\alpha$-alumina with $400 \mathrm{~nm}(0.4 \mu \mathrm{m})$ by SPS method and the effects of various process parameters have been extensively. According to their results, full densification can be attained at the temperature range of $1200^{\circ} \mathrm{C}$ to $1250^{\circ} \mathrm{C}$ and the grain size of the sintered body lies between $0.9 \mu \mathrm{m}$ and $1.6 \mu \mathrm{m}$. Further, it is indicated that there exists a temperature "window", with which full densification can be achieved without grain growth or with only very limited grain growth.

It has also indicated that high heating rates are favorable for attaining ceramics with ultrafine grains. According to Stanciu et al. ${ }^{15)}$, dense $\alpha$-alumina with ultrafine grains of about $500 \mathrm{~nm}$ has been synthesized at very high heating rate of $700^{\circ} \mathrm{C} / \mathrm{min}$ using SPS method. They also showed that the high heating rate of $250^{\circ} \mathrm{C} / \mathrm{min}$ was not enough to obtain dense $\alpha$-alumina with the grain size of less than $1 \mu \mathrm{m}$. Importance of heating rate in the attainment of ultrafinegrained structure has also examined by consolidating the same TM-alumina powder using SPS process ${ }^{16)}$ and high dense $\alpha$-alumina with $460 \mathrm{~nm} \sim 580 \mathrm{~nm}$ was obtained at $1200^{\circ} \mathrm{C}$ under the condition of $50^{\circ} \mathrm{C} / \mathrm{min}$ or $300^{\circ} \mathrm{C} / \mathrm{min}$, unlike the results by Stanciu et al..

Comparing with these previous results, SPS method enables to synthesize dense nano-structural $\alpha$-alumina with the grain size of less than $300 \mathrm{~nm}$ by consolidating TMalumina powder at the conditions of $1150^{\circ} \mathrm{C}$ and $100 \mathrm{MPa}$. Even in the case of using AA-alumina with the average size of $230 \mathrm{~nm}$, similar $\alpha$-alumina with the grain size of about $500 \mathrm{~nm}$ can be consolidated at the conditions of $1200^{\circ} \mathrm{C}$ and $100 \mathrm{MPa}$. Thus, SPS method has the capabilities of synthesizing nano-structured ceramics at low temperature and for short sintering time. It is also suggested that the control of various process parameters, such as the combination of heating rate and applied pressure, is important for the synthesis of nano-structured ceramics at low consolidation temperature.

\section{Summary}

Nano-structural and dense $\alpha$-alumina was synthesized with SPS method using two very fine $\alpha$-alumina powders (TM-alumina and AA-alumina) and the following conclusions were obtained;

(1) In the TM-alumina powder, nearly full densification can be attained at $1200^{\circ} \mathrm{C}$ under $30 \mathrm{MPa}$ and $1150^{\circ} \mathrm{C}$ under $100 \mathrm{MPa}$, respectively. In the AA-alumina powder, nearly full densification can be attained at $1200^{\circ} \mathrm{C}$ under $100 \mathrm{MPa}$. While, under the condition of $30 \mathrm{MPa}$, high temperature close to $1400^{\circ} \mathrm{C}$ is required for nearly full densification.

(2) Nano-structural $\alpha$-alumina with the grain size of less than $300 \mathrm{~nm}$ was synthesized at the condition of $1150^{\circ} \mathrm{C}$ and $100 \mathrm{MPa}$ using TM-alumina powder of $100 \mathrm{~nm}$. When AA-alumina powder of $230 \mathrm{~nm}$ was used as the starting material, similar dense $\alpha$-alumina with about $500 \mathrm{~nm}$ was synthesized at the condition of $1200^{\circ} \mathrm{C}$ and $100 \mathrm{MPa}$.

(3) Under the condition of $30 \mathrm{MPa}$, densification behavior was influenced by the difference of grain size of raw $\alpha-$ alumina powder, while the influence of grain size difference on the densification behavior was remarkably suppressed under $100 \mathrm{MPa}$.

(4) It was found that crystallite growth is remarkably suppressed in the SPS-consolidated aluminas by increasing the applied pressure from $30 \mathrm{MPa}$ to $100 \mathrm{MPa}$.

\section{Acknowledgement}

The present work was supported by a Grant-in-aid for Scientific Research (B) [No.16360364] given by The 
Ministry of Education, Culture, Sports, Science and Technology.

\section{References}

1) Y.Makino: "Synthesis of nano-structured materials with pulsed high current heating", J. High Temperature Soc., 31(2005)202-208 (in Japanese).

2) R.Dobedoe, G.D.West and M.H.Lewis: "Spark plasma sintering of ceramics", Bull. EcerS, 1(2003)19-24.

3) M.Omori: "Sintering, consolidation, reaction and crystal growth by spark plasma system", Mater. Sci. and Eng., A287(2000)183-188.

4) M.Tokita, M.Kawahara, M.Sonoda, M.Omori, A.Okubo and T.Hirai: "Preparation and triborogical characterization of $\mathrm{ZrO}_{2}(3 \mathrm{Y})+20 \mathrm{wt} \% \mathrm{Al}_{2} \mathrm{O}_{3} / \mathrm{SUS} 410 \mathrm{~L}$ stainless steel composite functionally graded materials fabricated by spark plasma sintering method", J. Jpn. Soc. Powder Powder Metallurgy, 52(1999)269-276.

5) K.Liu, X.Dong and Z.Jiuxing: "The effects of $\mathrm{La}$ on thermoelectric properties of $\mathrm{La}_{\mathrm{x}} \mathrm{Co}_{4} \mathrm{Sb}_{12}$ prepared by MA-SPS", Mater. Chem. Phys., 96(2006)371-375.

6) T.Takeuchi, E.Bétourné, M.Tabuchi, H.Kageyama Y.Kobayashi, A.Coats, F.Morrison, D.C.Sinclair and A.R.West: "Dielectric properties of spark-plasmasintered $\mathrm{BaTiO}_{3}$ ", J. Mater. Sci., 34(1999)917-924.

7) Y.Zheng, S.Wang, M.You, H.Tan and W.Xiong: "Fabrication of nanocomposite Ti(C,N)-based cermet by spark plasma sintering", Mater. Chem. \& Phys., 92(2005)64-72.

8) S.Yamamoto: "Development of non-reciprocal transmission device using extremely thin ceramic platelet prepared by SPS method", J. High Temperature Soc., 31(2005) 180-185 (in Japanese).

9) Y.Makino, T.Mori, H.Eguchi, H.Saito, B.Kyoh and S.Miyake: "Preferentially oriented anatase nanopowder densified by puled high current heating", J. Mater. Sci. Lett., 22(2003)403-405.

10) Y.Makino, T.Mori, H.Eguchi, T.yoshioka, H.Saito, B.Kyoh and S.Miyake: "Dense nano-structured and preferentially-oriented anatase synthesized by puled high current heating", J. Jpn. Soc. Powder Powder Metallurgy, 52(2005)805-811.

11) Y.Makino: "Crystallographic behaviors of nanopowder anatase consolidated by SPS method", 6th
Pacific RIM conference on Ceramic and Glass Technology, Maui, Hawaii, USA, (2005).

12) Z.Shen, M,Johnsson, Z.Zhao and M.Nygren: "Spark plasma sintering of alumina", J. Am. Ceram. Soc., 85 (2002) 1921-1927.

13) S.-T.Oh, K.Tajima and M.Ando: "Strengthening of porous alumina by pulse electric current sintering and nanocomposite processing", J. Am. Ceram. Soc., 83 (2000) 1314-1316.

14) M.Nygren and Z.Shen: "On the preparation of bio-, nano- and structural ceramics and composites by spark plasma sintering", Solid State Sci., 5(2003)125-131.

15) L.A.Stanciu, V.Y.Kodash and J.R.Groza: "Effects of heating rate on densification and grain growth during field-assisted sintering of $\alpha-\mathrm{Al}_{2} \mathrm{O}_{3}$ and $\mathrm{MoSi}_{2}$ powders", Metall. Mater. Trans., 32A(2001)2633-2638.

16) Y.Zhou, K.Hirao, Y.Yamauchi and S.Kanzaki: "Densification and grain growth in pulse electric current sintering of alumina", J. Euro. Ceram. Soc., 24(2004)3465-3470.

17) Y.Makino, T.Nakanishi and H.Saito: "Estimation of Homogeneity in Pulsed High Current Sintering by Crystallographic Character of Consolidated Anatase", J. Jpn. Soc. Powder Powder Metallurgy, 53(2006)909914.

18) S.W.Wang, L.D.Chen and T.Hirai: "Densification of $\mathrm{Al}_{2} \mathrm{O}_{3}$ powder using spark plasma sintering", $\mathrm{J}$. Marer. Res., 15(2000)982-987.

19) S.W.Wang, L.D.Chen, T.Hirai and Y.S.Kang: "Microstructure inhomogeneity in $\mathrm{Al}_{2} \mathrm{O}_{3}$ sintered bodies formed during the plasma-activated sintering process", J. Mater. Sci. Letts., 18(1999)1119-1121.

20) L.Gao, J.S.Hong, H.Miyamoto and S.D.D.L.Torre: "Bending strength and microstructure of $\mathrm{Al}_{2} \mathrm{O}_{3}$ ceramics densified by spark plasma sintering", J. Euro. Ceram. Soc., 20(2000)2149-2152.

21) R.S.Mishra and A.K.Mukherjee: "Electric pulse assisted rapid consolidation of ultrafine grained alumina matrix composites", Mater. Sci. and Emg., A287(2000)178-182.

22) S.H.Risbud, C.-H. Shan, A.K.Mukherjee, M.J.Kim, J.S.Bow and R.A.Holl: "Retention of nanostructure in aluminum oxide by very rapid sintering at $1150^{\circ} \mathrm{C}$, J. Mater. Res., 10(1995)237-239. 